\title{
Visualization and Measurement of Boiling Flow Behaviors in Parallel Mini-channel Heat Exchanger by Neutron Radiography
}

\author{
Hitoshi Asano ${ }^{1, a}{ }^{*}$, Hideki Murakawa ${ }^{1, b}$, Ryosuke Moriyasu ${ }^{1, c}$, \\ Katsumi Sugimoto ${ }^{1, d}$, Yohei Kubo ${ }^{2}$, Kazuhisa Fukutani ${ }^{2}$, Daisuke Ito ${ }^{3, e}$ \\ and Yasushi Saito ${ }^{3, f}$ \\ ${ }^{1}$ Department of Mechanical Engineering, Graduate School of Engineering, Kobe University \\ 1-1 Rokkodai, Nada-ku, Kobe 657-8501, Japan \\ ${ }^{2}$ Mechanical Engineering Research Laboratory, Kobe Steel, Ltd. \\ 1-5-5, Takatsukadai, Nishi-ku, Kobe 651-2271, Japan \\ ${ }^{3}$ Institute for Integrated Radiation and Nuclear Science, Kyoto University \\ 2 Asashiro-Nishi, Kumatori-cho, Sennan-gun, Osaka 590-0494, Japan \\ aasano@mech.kobe-u.ac.jp, 'murakawa@mech.kobe-u.ac.jp, ${ }^{c} 189 t 373 t @ s t u . k o b e-u . a c . j p$, \\ ${ }^{d}$ sugimoto@mech.kobe-u.ac.jp, ${ }^{\mathrm{e}}$ itod@rri.kyoto-u.ac.jp, ${ }^{\mathrm{f}} \mathrm{ysaito@rri.kyoto-u.ac.jp}$
}

Keywords: Compact Heat Exchanger, Parallel Channel, Evaporator, Void Fraction, HFC134a, Neutron Radiography

\begin{abstract}
Boiling two-phase flows in cross-flow type mini-channel evaporator were visualized by neutron radiography. Refrigerant vertically upward flow of $\mathrm{HFC} 134 \mathrm{a}\left[\mathrm{CH}_{2} \mathrm{FCF}_{3}\right]$ in 21 parallel channels with the hydraulic diameter of $1.47 \mathrm{~mm}$ was heated by the heating medium of fluorocarbon FC3283. Void fraction distributions of evaporating two-phase flows were measured by neutron radiography. The effect of the inlet orifices for each refrigerant channel to prevent flow instability was evaluated. The refrigerant was supplied to the test section as subcooled liquid with the mass flux of 50 to $100 \mathrm{~kg} /\left(\mathrm{m}^{2} \mathrm{~s}\right)$. The heating medium was supplied with the mass flux of 460 and $920 \mathrm{~kg} /\left(\mathrm{m}^{2} \mathrm{~s}\right)$ and at the inlet temperature of 47.1 to $67.2^{\circ} \mathrm{C}$. As the result, it is shown that void fraction close to the inlet of heating medium was relatively higher. Flow instability of boiling flows and the effect of the inlet orifices were not observed.
\end{abstract}

\section{Introduction}

Compactness and decrease in temperature difference between two fluids are still important issues in developing heat exchangers. Especially, decrease in the temperature difference is required for the improvement in performance of energy systems, such as waste heat recovery, refrigerating and air-conditioning systems. One approach is the increase in heat transfer area density. On the other hand, for refrigeration and air-conditioning machines, reduction of the refrigerant charging amount is strongly required to satisfy the Kigali agreement of Montreal Protocol, because popular refrigerants have high global warming potential (GWP). The reduction in the channel diameter is effective way for the both requirements.

Microchannel compact heat exchanger manufactured by diffusion bonding process is developed. Smaller refrigerant channel diameter leads to larger pressure loss of refrigerant flows. Larger pressure loss requires larger pumping power. For an evaporator and condenser, the larger pressure loss causes temperature decrease, because the refrigerant is under the saturation condition. Therefore, microchannel heat exchanger has many parallel channels, and refrigerant flow is distributed into the parallel channels to decrease the mass flow rate through each channel. For a liquid or gas single-phase flow application, uniform flow distribution among channels is 
easily obtained by appropriate design of the header for flow distribution. However, in the case where the refrigerant flows with evaporation or condensation, maldistribution often occurs, regardless of the inlet flow condition. The maldistribution causes deterioration in the heat transfer performance.

Such parallel microchannel systems are investigated for the application of the cooling device of electro equipment. Huang and Thome [1] conducted boiling flow experiments in 67 parallel microchannel cooling equipment using three types of refrigerant. The channel hydraulic diameter was $0.1 \mathrm{~mm}$. As a result; it was shown that boiling flows could be stabilized by an inlet orifice for each channel, and pressure loss through the straight section except of the inlet orifice decreased. Dário, et al. [2] experimentally evaluated the pressure drop of HFC-134a boiling flows through 9 parallel microchannels with the hydraulic diameter of $0.77 \mathrm{~mm}$. Frictional and acceleration contributions to the pressure drop were analyzed. In these studies, parallel channels were symmetrically heated with constant heat flux. Kuroki, et al. [3] conducted HFC-32 boiling flow experiments in 2 parallel channels with the diameter of $1.0 \mathrm{~mm}$. The effect of nonuniformly heating on heat transfer coefficient was evaluated. It was reported that under the nonuniformly heating condition, the heat transfer coefficient of the flow with higher heating load became lower, and overall heat transfer coefficient of the parallel channels decreased by nonuniform heating. The deterioration in heat transfer coefficient might be caused by refrigerant maldistribution.

In this study, boiling two-phase flows in cross-flow type mini-channel evaporator manufactured by diffusion bonding were visualized by neutron radiography. Liquid refrigerant was heated by a heating medium. The effects of mass flow rate of the refrigerant, mass flow rate and inlet temperature of the heating medium on heat transfer rate and void fraction distribution were evaluated.

\section{Experimental setup and method}

A schematic diagram of experimental apparatus is shown in Fig. 1. HFC-134a, whose chemical formula is $\mathrm{CH}_{2} \mathrm{FCF}_{3}$, was used as the refrigerant, and fluorocarbon FC-3283 was used as the heating medium. The attenuation of neutron is quite low for FC3283 because FC3283 does not include hydrogen. Subcooled liquid refrigerant was supplied to the test section through a preheater by a gear pump. The refrigerant inlet temperature was measured by a K-type sheathed thermocouple inserted in the channel at the downstream of a mixing section. A tank was connected to the upstream of the pump to absorb volume change due to boiling. Refrigerant pressures were measured at the inlet and outlet of the test section. On the other hand, the heating medium was supplied from a temperature controlled bath. Inlet and outlet temperatures were measured by inserted thermocouples. Mass flow rates of both fluids were measured by mass flow meter.

A schematic of tested heat exchanger is shown in Fig. 2. Refrigerant and heating medium channels were formed on a thin stainless steel sheet by chemical etching process, individually. Then, the sheets was stacked by diffusion bonding process. The cross-sectional shape of channels was semi-circular with the hydraulic diameter of $1.47 \mathrm{~mm}$ as shown in Fig. 2 (b). The same channel shape was applied to both fluids. The number of channels was 21 for the refrigerant and 20 for the heating medium. The channels were set in crossflow arrangement as shown in Fig. 2(a). The temperature of the heating medium would be higher at the right channel near the heating medium inlet. The test section was placed vertically to form upward boiling flows. Two types of refrigerant channel were used, namely, Type I with an inlet orifice for each channel and Type II without inlet orifice.

Neutron radiography experiments were carried out at B4 port of Kyoto University Research Reactor. The neutron beam was irradiated from the front face. The exposure time was set to 30 
seconds. Since the width of the radiation field was narrower than that of the heat transfer area, radiograph was obtained for 5 sections by moving horizontally. Figure 3 shows an original visualized image of the center section. The pixel size was $87.9 \mu \mathrm{m} /$ pixel. Void fractions, $\alpha$, were measured from three radiographs of two-phase flows, the liquid single-phase flow and the vapor single-phase flow.

Assuming that the brightness of a visualized image is proportional to the beam intensity on a scintillation converter and neglecting the attenuation term due to a gas phase, the brightness of two-phase flow image $S_{\mathrm{TP}}(x, y)$, the image of liquid single-phase flow $S_{0}(x, y)$, i.e., $\alpha(x, y)=0$, and the image of vapor single-phase flow $S_{1}(x, y)$, i.e., $\alpha(x, y)=1$, are expressed as the following equations [4].

$$
\begin{aligned}
& S_{T P}(x, y)=G(x, y) \exp \left[-\rho_{w} \mu_{m w} t_{w}(x, y)-\{1-\alpha(x, y)\} \rho_{L} \mu_{m L} t_{c}(x, y)\right]+O_{T P}(x, y) \\
& S_{0}(x, y)=G(x, y) \exp \left[-\rho_{w} \mu_{m w} t_{w}(x, y)-\rho_{L} \mu_{m L} t_{c}(x, y)\right]+O_{0}(x, y) \\
& S_{1}(x, y)=G(x, y) \exp \left[-\rho_{w} \mu_{m w} t_{w}(x, y)\right]+O_{1}(x, y)
\end{aligned}
$$

where $\rho$ and $\mu_{\mathrm{m}}$ are the density and mass attenuation coefficient, respectively. $t_{\mathrm{w}}$ and $t_{\mathrm{c}}$ is thickness of wall and channel along a neutron beam, respectively. $G(x, y)$ is the gain and depends on the position due to a non-flatness of the initial beam intensity and of the sensitivity in a imaging system. $O_{\mathrm{TP}}(x, y), O_{0}(x, y), O_{1}(x, y)$ are the offset value in brightness. In this study, the dark current $O(x, y)$ was used as the offset values. Using equations (1) to (3), a two-dimensional void fraction distribution can be expressed as

$$
\alpha(x, y)=\frac{\ln \left[\left(S_{T P}(x, y)-O(x, y)\right) /\left(S_{0}(x, y)-O(x, y)\right)\right]}{\ln \left[\left(S_{1}(x, y)-O(x, y)\right) /\left(S_{0}(x, y)-O(x, y)\right)\right]}
$$

Experimental conditions are shown in Table 1. Experiments were carried out for varied refrigerant mass flux of 50 and $100 \mathrm{~kg} /\left(\mathrm{m}^{2} \mathrm{~s}\right)$, heating medium mass flux of 460 and 920 $\mathrm{kg} /\left(\mathrm{m}^{2} \mathrm{~s}\right)$, and heating medium inlet temperature of 29.0 to $67.2^{\circ} \mathrm{C}$.

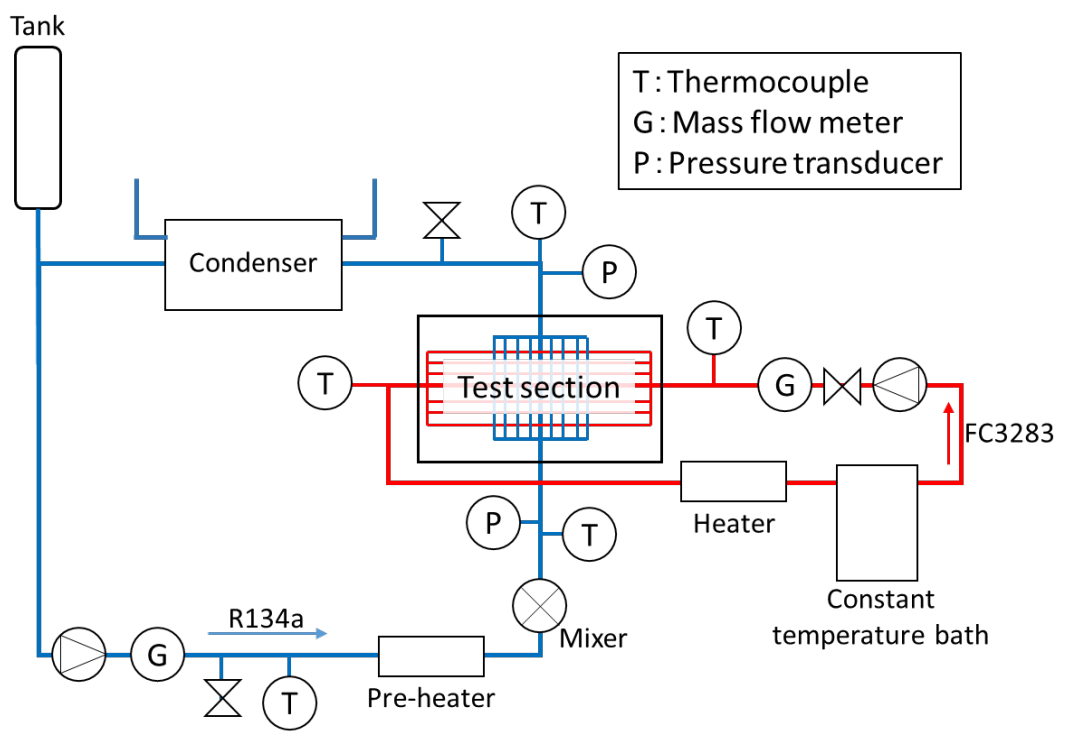

Fig. 1. Schematic diagram of experimental apparatus. 


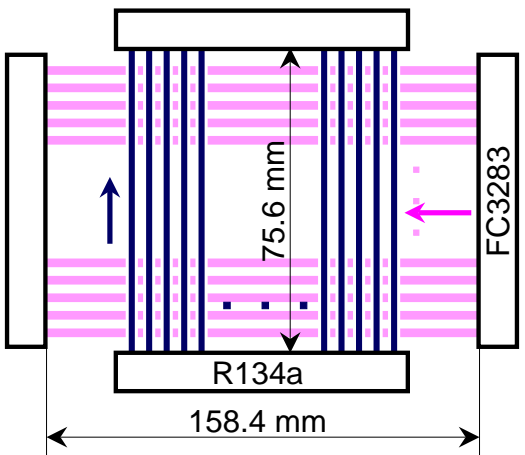

(a) Channel arrangement

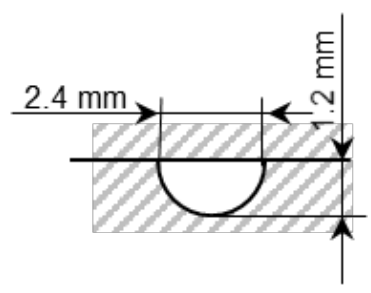

(b) Cross-section

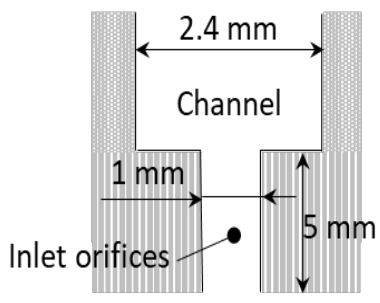

(c) Inlet orifice

Fig. 2. Test section.

Table 1. Experimental condition.

\begin{tabular}{|c|c|c|c|}
\hline & & Type I (with inlet orifices) & Type II \\
\hline \multirow{3}{*}{ Refrigerant } & Mass flow rate (Mass flux) & $142.5,285 \mathrm{~g} / \mathrm{min}\left(50,100 \mathrm{~kg} /\left(\mathrm{m}^{2} \mathrm{~s}\right)\right)$ \\
\cline { 2 - 4 } R134a & Inlet subcooling degree & $3.14 \sim 4.66 \mathrm{~K}$ & $0.60 \sim 2.93 \mathrm{~K}$ \\
\cline { 2 - 4 } & Inlet pressure & $0.632 \sim 0.659 \mathrm{MPa}$ & $0.570 \sim 0.619 \mathrm{MPa}$ \\
& (Saturation temperature) & $\left(23.3 \sim 24.7^{\circ} \mathrm{C}\right)$ & $\left(19.9 \sim 22.6^{\circ} \mathrm{C}\right)$ \\
\hline \multirow{2}{*}{ Heating } & Mass flow rate (Mass flux) & $1.25,2.5 \mathrm{~kg} / \min \left(460,920 \mathrm{~kg} /\left(\mathrm{m}^{2} \mathrm{~s}\right)\right)$ \\
medium & Re for liquid flow & \multicolumn{2}{|c|}{450,900} \\
\cline { 2 - 4 } FC3283 & Inlet temperature & $47.3 \sim 48.5^{\circ} \mathrm{C}$ & $47.1 \sim 48.5^{\circ} \mathrm{C}$ \\
& & $65.1 \sim 67.2^{\circ} \mathrm{C}$ & $64.7 \sim 67.2^{\circ} \mathrm{C}$ \\
\hline
\end{tabular}

\section{Experimental results and discussion}

Void fraction distribution

Void fraction can be measured for each pixel. Spatial average void fractions were calculated in the area of 11 by 11 pixels. Eleven pixels were equivalent to 0.97 $\mathrm{mm}$. Then, one-dimensional void fraction distributions were obtained by moving average to the flow direction for each channel. Void fraction distributions are shown in Figs. 4 by color scale. Figures 4 (a) and (b) show the results for Type I with inlet orifices and Type II without orifices, respectively. The heating medium was flowing from the right to left side.

Void fraction became higher to the downstream due

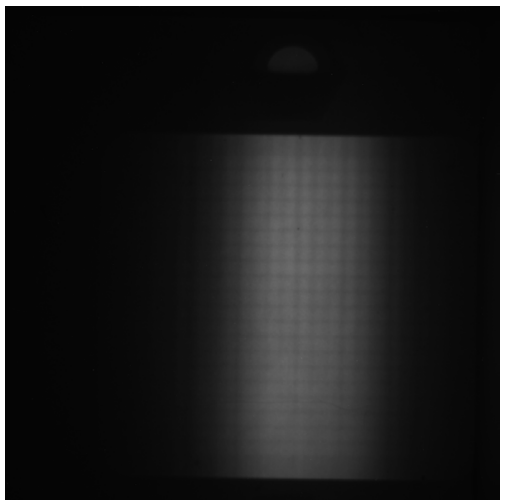

Fig. 3. Original visualized image of the center section of the heat transfer to boiling. The distributions were seemed to be continuous among channels. For two-phase flows in parallel channels, a maldistribution of refrigerant flow sometimes occurs and produces a channel whose mass flow rate and exit vapor quality is quite different form the other channels. Since the distribution was continuous, such flow instability might not occur in this system. Void fraction was higher the closer to the right and left edge. Mass flow rate might be higher the closer to the center channel, because the inlet and outlet ports were at the horizontal center of the header. Void fraction on the right side close to the heating medium inlet was higher than the left side. The difference might be caused by the difference in temperature difference between the refrigerant and heating medium. On the other hand, horizontal distributions of void fraction tend to become uniform for the higher mass flow rate of the heating medium, because the temperature change of the heating medium became smaller due to the higher heat capacity flow rate. 
In comparison of the test sections, the void fraction of Type I was lower than Type II. The difference was caused by the difference in the operating pressure of refrigerant.

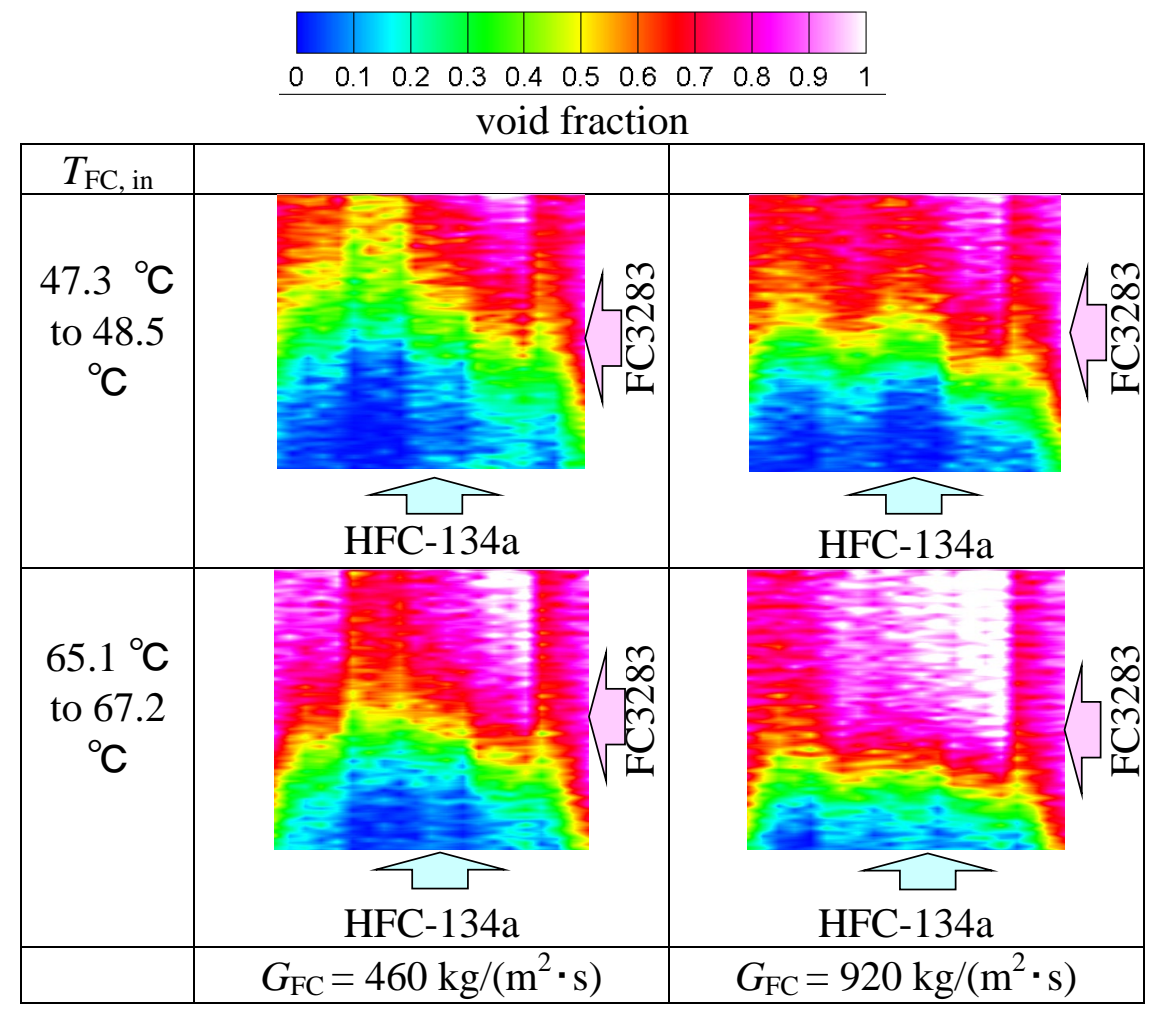

(a) Type I (with inlet orifices)

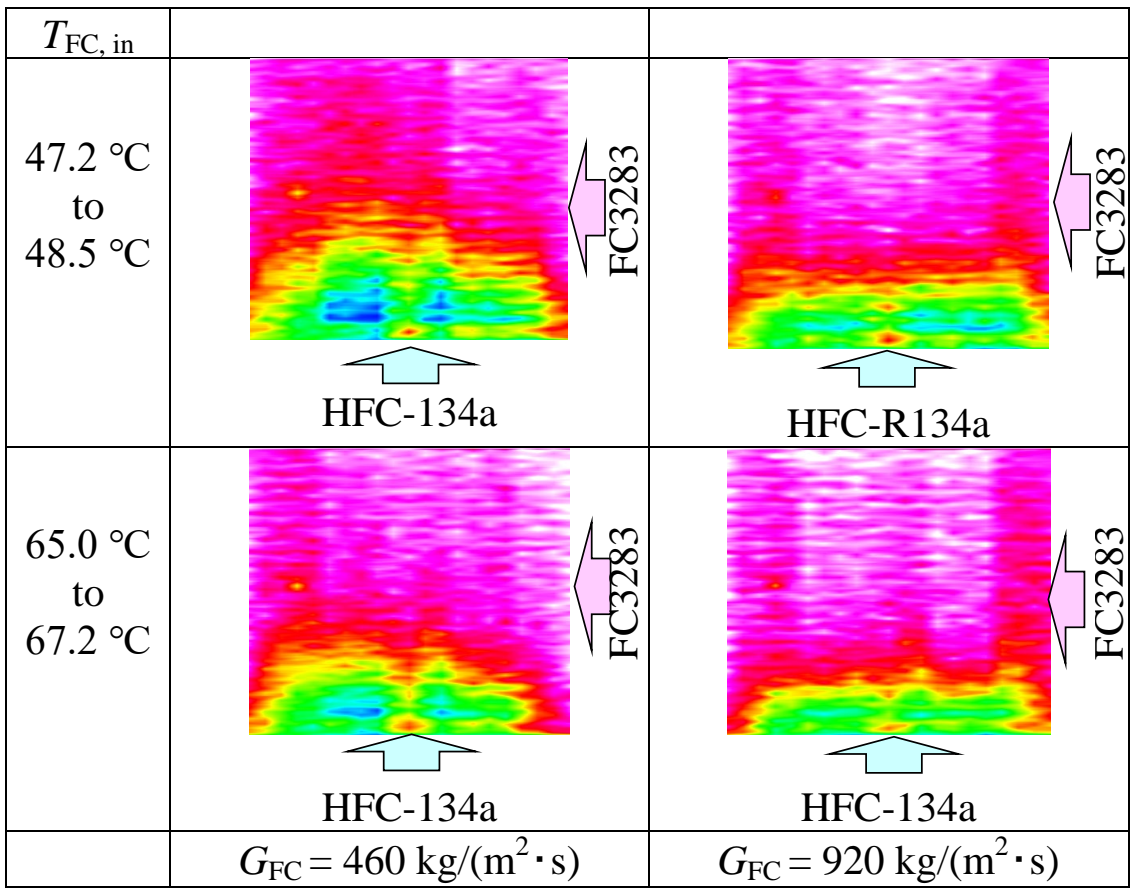

(b) Type II (without inlet orifice)

Fig. 4. Void fraction distribution $\left(G_{R}=100 \mathrm{~kg} /\left(\mathrm{m}^{2} \cdot \mathrm{s}\right)\right)$ 


\section{Heat transfer rate}

Heat transfer rate was calculated from temperature change and heat capacity flow rate of the heating medium. Measured heat transfer rates are shown in Fig. 5. The measured heat transfer rate increased with increasing inlet temperature of the heating medium due to the increase in temperature difference of heat exchange. While the effect of mass flow rate of the refrigerant was little, the effect of mass flow rate of the heating medium was noticeable. Higher mass flow rate produced larger heat transfer rate. There are two possible reasons. One is the decrease in temperature change of the heating medium due to the increase in heat capacity flow rate. The decrease leads to the increase in temperature difference between fluids. The other is the improvement of heat transfer in heating medium. Total thermal resistance of two fluids can be expressed as the summation of thermal resistance in the refrigerant, the stainless steel wall, and the heating medium. Since the heat transfer coefficient of boiling flow is quite higher than that of liquid single-phase flow, total thermal resistance might be dominated by the thermal resistance in the heating medium flow.

As shown in void fraction distribution, heat transfer rate of Type II was larger than that of Type I with the inlet orifices. The difference might be caused by the difference in refrigerant pressure. In the experiments for Type II, flow instability was not observed. Since the inlet orifices are used to stabilize the boiling flows, the orifices might not have an effect on the heat transfer performance.

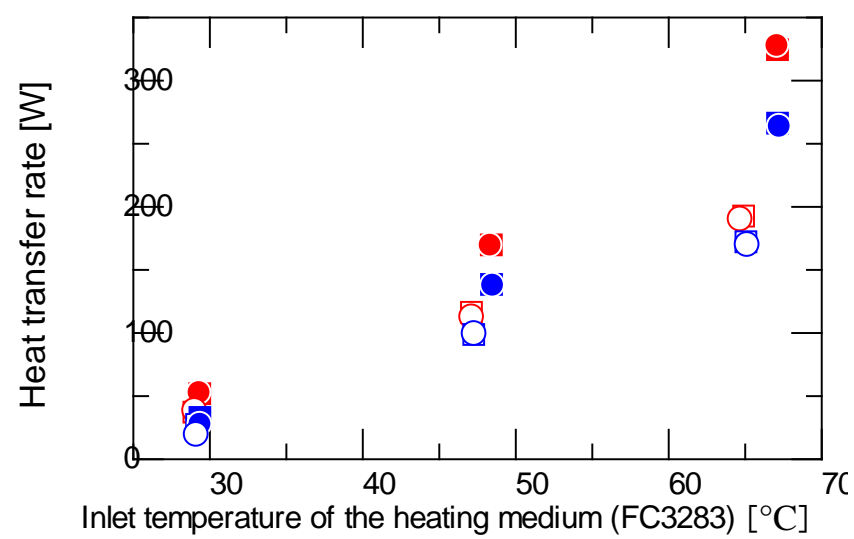

\begin{tabular}{|l|c|c|c|}
\hline \multirow{2}{*}{} & $\begin{array}{c}\text { mass flux } \\
\mathrm{R} 134 \mathrm{a} \\
{\left[\mathrm{kg} /\left(\mathrm{m}^{2} \cdot \mathrm{s}\right)\right]}\end{array}$ & \multicolumn{2}{|c|}{$\begin{array}{c}\text { mass flux FC3283 } \\
{\left[\mathrm{kg} /\left(\mathrm{m}^{2} \cdot \mathrm{s}\right)\right]}\end{array}$} \\
\cline { 2 - 4 } Type I & 50 & 0 & 920 \\
\cline { 2 - 4 } & 100 & $\square$ & \\
\hline \multirow{2}{*}{ Type II } & 50 & $\bigcirc$ & \\
\cline { 2 - 4 } & 100 & $\square$ & \\
\hline
\end{tabular}

Fig. 5. Heat transfer rate.

\section{Summary}

In this study, boiling two-phase flows of HFC-134a in 21 parallel mini-channels were visualized by neutron radiography, and void fraction distributions were measured from radiographs. The refrigerant was heated by fluolocarbon FC3283 in 20 parallel mini-channels. As a result, it was shown that void fraction was higher the closer to the inlet of the heating medium. Horizontal distributions of void fraction tend to become uniform by increasing mass flow rate of the heating medium. Flow instability was not confirmed from the visualized results.

\section{Acknowledgement}

This work has been carried out in part under the Visiting Researchers Program of Kyoto University Institute for Integrated Radiation and Nuclear Science. 


\section{References}

[1] H. Huang, J. R. Thome, An Experimental Study on Flow Boiling Pressure Drop in Multimicrochannel, Experimental Thermal and Fluid Science, 80 (2017) 391-407. https://doi.org/10.1016/j.expthermflusci.2016.08.030

[2] E. R. Dário, J. C. Passos, M. L. Sánchez Simón, L. Tadrist, Pressure Drop during Flow Boiling inside Parallel Microchannels, International Journal of Refrigeration, 72 (2016) 111123. https://doi.org/10.1016/j.ijrefrig.2016.08.002

[3] K. Kurose, K. Miyata, Y. Hamamoto, H. Mori, Characteristics of Flow Boiling Heat Transfer in Non-Uniformly Heated Parallel Mini-Channels, Trans. of the JSRAE, 35(2) (2018), 101-108. https://doi.org/10.1615/TFEC2018.che.021663

[4] N. Takenaka, H. Asano, T. Fujii, M. Matsubayashi, "A Method for Quantitative Measurement by Thermal Neutron Radiography", Nondestructive Testing and Evaluation, 16 (2001), 345-354. https://doi.org/10.1080/10589750108953089 